\title{
Characterizing opioid use disorder patients who have received medication trials with both buprenorphine and methadone
}

\author{
Christine M Wilder ${ }^{1,2^{*}}$, Paul Horn ${ }^{1,3}$, Theresa Winhusen ${ }^{2}$ \\ From 2014 Addiction Health Services Research (AHSR) Conference \\ Boston, MA, USA. 15-17 October 2014
}

Since the approval of buprenorphine for treatment of opioid use disorder (OUD) in 2002, it has become increasingly likely that some individuals with OUD will have been treated with both buprenorphine and methadone at different points in time. However, this emergent group of patients has not been well described. We completed a retrospective cohort study of individuals at the Cincinnati Veterans Administration with treatment episodes for both buprenorphine and methadone and compared this group with individuals who received treatment with buprenorphine only or methadone only. Between January 1, 2006, and May 1, 2014, 163 veterans had both buprenorphine and methadone treatment episodes for OUD. We extracted information from the local administrative and pharmacy databases to describe these individuals. Individuals with treatment episodes for both medications had significantly higher levels of comorbidity with other substance use disorders (specifically, alcohol, benzodiazepine, cannabis, and cocaine use disorders) as well as mood and anxiety disorders than those who received either buprenorphine or methadone only. They also used a disproportionate amount of urgent and emergency services compared to individuals prescribed either buprenorphine or methadone only (mean of 17.8 billable days versus 11.3 for buprenorphine only and 10.4 for methadone only, $\mathrm{p}<0.0001$ ). We conclude that these patients represent a treatmentresistant group that would benefit from earlier identification and more intensive intervention.

\footnotetext{
* Correspondence: Christine.wilder@uc.edu

'Department of Veterans Affairs Medical Center, Cincinnati, OH, 45220, USA Full list of author information is available at the end of the article
}

\section{Authors' details}

'Department of Veterans Affairs Medical Center, Cincinnati, OH, 45220, USA ${ }^{2}$ Department of Psychiatry and Behavioral Neuroscience, University of Cincinnati College of Medicine, Cincinnati, OH, 45229, USA. ${ }^{3}$ Department of Pediatrics, Cincinnati Children's Hospital Medical Center, Cincinnati, $\mathrm{OH}$, 45229, USA.

Published: 20 February 2015

doi:10.1186/1940-0640-10-S1-A71

Cite this article as: Wilder et al: Characterizing opioid use disorder patients who have received medication trials with both buprenorphine and methadone. Addiction Science \& Clinical Practice 2015 10(Suppl 1):A71.

Submit your next manuscript to BioMed Central and take full advantage of:

- Convenient online submission

- Thorough peer review

- No space constraints or color figure charges

- Immediate publication on acceptance

- Inclusion in PubMed, CAS, Scopus and Google Scholar

- Research which is freely available for redistribution 